\title{
POLÍTICAS DE FOMENTO A LA COMPETITIVIDAD DE LA PEQUEÑA EMPRESA
}

\author{
Braulio Vargas \\ Universidad ESAN \\ bvargas@esan.edu.pe
}

\section{Resumen}

En enero del 2003, el gobierno peruano emprendió un proceso de descentralización y transferencia de competencias a los gobiernos locales y regionales, con el propósito de impulsar el desarrollo a través del crecimiento económico y la generación de empleo con énfasis en la pequeña empresa. La evidencia muestra, empero, que los esfuerzos realizados no fueron efectivos debido a la falta de políticas planificadas y articuladas con los objetivos del desarrollo.

En este sentido, en el presente trabajo se plantea un marco de referencia para el diseño de políticas locales que incidan en el dinamismo económico, la articulación del tejido empresarial local con sistemas externos y la creación de bienestar; todo ello mediante el fomento a la competitividad de la pequeña empresa. Este instrumento permite diferenciar medidas de fomento en función de considerar la vinculación de la actividad emprendedora con el territorio, los factores de éxito de las empresas innovadoras y el ciclo de vida asociado al potencial de innovación y crecimiento de la firma.

Palabras clave: competitividad, innovación, pequeña empresa, políticas locales, desarrollo económico local, ciclo de vida.

\begin{abstract}
In 2003 the Peruvian government launched a second wave of decentralization and devolution initiatives to the sub-national governments. The move aimed at fostering development, economic growth and job creation with a strong focus on small companies. However, evidence shows these efforts failed because properly planned policies linked to development objectives were lacking. A reference framework is proposed to design local policies that will add economic momentum, relate the local business network to external systems, and create wellbeing by fostering small business competitiveness. To help identify several types of development measures, the paper proposes to take account of the relation between the business activity and its territory, the key factors of success of innovative companies, and the business's life cycle as related to the potential for innovation and growth.
\end{abstract}

Key words: competitiveness, innovation, small company, local policies, local economic development, life cycle. 


\section{La pequeña empresa como fuente de competitividad territorial y desarrollo económico local en tiempos de globalización}

\subsection{El desarrollo local bajo el influjo de la globalización}

Al revisar los hitos en la ruta de la prosperidad económica de los países y economías desarrolladas, cabe la posibilidad de identificar criterios comunes que permitan entender cómo esa prosperidad tuvo un correlato con el desarrollo de espacios locales y regionales, que ha precedido al desarrollo nacional o macrodesarrollo. Así, 500 años atrás los estados europeos estaban fragmentados en pequeños territorios. Sus ciudades contaban con economías locales que favorecían las actividades económicas progresivamente más especializadas (de alto valor) y la conexión con otras economías locales, lo que generaba eficiencia colectiva y complementariedad económica y social, y trajo prosperidad a sus ciudadanos y empresas. Esta ruta evolutiva, que continúa hasta el día de hoy, no ha sido el resultado del ensayo «prueba-error», sino, más bien, el producto de políticas de fomento concordantes con las realidades, las necesidades, las capacidades y las oportunidades locales $\mathrm{y}$, posteriormente, regionales (Reinert, 1994).

Algunas de las políticas de fomento económico más exitosas y sostenidas datan de la época del descubrimiento de América. En ciudades como Venecia y Ámsterdam, entre muchas otras, se dictaron políticas explícitas para proteger, fortalecer e impulsar la actividad económica local en torno a industrias estratégicas. Políticas como el impulso a la capacidad inventiva de los emprendedores locales y a la investigación tuvieron relación directa con la búsqueda de oportunidades económicas diferenciadas. La institución de la figura de las patentes y los derechos de propiedad intelectual sirvieron, asimismo, como instrumentos para crear barreras a la fuga de inventores y emprendedores locales.

El posicionamiento obtenido por muchos de los espacios locales se ha mantenido incluso hasta el siglo XX, tal como lo atestigua la existencia de polos de desarrollo en ciudades de Italia, Alemania, Holanda, Inglaterra y Francia, entre otros países. Los aportes de expertos como Huntington (1997) llevan a pensar en una globalización preexistente a la actual que estuvo concentrada en Europa. Los beneficios sociales, económicos y políticos para los futuros países europeos descansaban sobre la alta movilidad de los factores de producción hacia múltiples regiones y localidades donde había una actividad económica superior.

Este primer punto de análisis tiene por objetivo plantear la siguiente tesis: la actividad económica descentralizada (con múltiples anclajes locales y sistemas productivos locales especializados) conduce a la prosperidad. El contraste se puede encontrar en la evolución de los países de América Latina, cuyas economías se han centralizado en torno a los centros de poder político -reflejado a través de los gobiernos-, el sistema competente en el diseño del modelo de planificación del desarrollo nacional, sea este centralizado o descentralizado. La centralización de las economías latinoamericanas continúa, en la mayoría de los casos, invariable, al igual que los niveles de desarrollo, prosperidad y bienestar de sus sociedades.

Stiglitz (2002) advierte que, por ejemplo, el régimen comunista de la otrora 
Unión Soviética condujo al país a un estado insostenible de manejo económico, pues la planificación centralizada de la economía no permite recolectar y procesar la información sobre las oportunidades y potencialidades reales de los espacios locales.

Una reflexión para los gestores de políticas de países en vías de desarrollo es que el aprovechamiento de los beneficios de la globalización está influenciado por las oportunidades de descentralizar las decisiones de desarrollo en torno a espacios locales y regionales relevantes. Consecuentemente, el fomento de la competitividad territorial y de la actividad emprendedora de alto valor es tema obligado en la agenda política, social y económica. Dicho en otros términos, la influencia de la globalización tiende a ser positiva para un país o economía si estos cuentan con sectores sociales y económicos emergentes desde una perspectiva local.

En el caso peruano, el proceso de descentralización iniciado en el 2003 implica un esfuerzo por crear oportunidades y levantar potencialidades desde los territorios locales y regionales, que beneficien al resto de actores que coexisten dentro de un espacio de demarcación territorial políticoadministrativa (el país).

En este marco, la descentralización de las decisiones y opciones para el desarrollo equivale a un medio, mientras que la transferencia de competencias y prerrogativas a los gobiernos descentralizados (locales y regionales) equivale al instrumento para posibilitar el desarrollo.

Entre las competencias transferidas, el desarrollo económico local resulta un factor clave para alentar el surgimiento de economías especializadas ancladas en un espacio local, pero conectadas a otros espacios locales para crear un polo económico de alcance regional. Pero si no existen políticas consistentes y explícitas para orientar este proceso de mediano y largo aliento, es poco probable que los niveles de desarrollo, prosperidad y bienestar evolucionen positivamente.

Más aun, si existiesen políticas consistentes y explícitas para promover el desarrollo económico descentralizado y diversificado a lo largo del territorio nacional, también sería necesario contar con el público objetivo que se beneficie de las políticas. Este público objetivo, en materia de desarrollo económico local, comprende principalmente la pequeña empresa, el clima de negocios, el espíritu emprendedor local, las inversiones, las facilidades de infraestructura y de servicios, la capacidad de los actores sociales, entre otros.

Los sujetos de análisis y atención en el presente artículo son las pequeñas empresas, en primer lugar, y los emprendimientos locales, en segundo término. Siendo así, cabe preguntar a los receptores de competencias y prerrogativas en materia de desarrollo económico local lo siguiente: ¿están los gobiernos locales y regionales preparados para combinar sus recursos y capacidades con aquellos de las sociedades y territorios situados en su entorno de influencia?, ¿están siendo las pequeñas empresas consideradas dentro de los programas y proyectos de desarrollo emprendidos por los gobiernos descentralizados?, ¿se han contemplado inversiones públicas que complementen las de los actores económicos locales?, ¿se ha planificado la competitividad territorial o solamente se prevé la programación de medidas de fomento a la inversión, sin garantía de que existan beneficios reales para la economía local? 


\subsection{La pequeña empresa en el centro de la competitividad y el desarrollo económico local}

En este punto, el objetivo es vincular la noción de competitividad con la de desarrollo económico local. Ambas nociones combinadas son primordiales para entender el alcance de las competencias de los gobiernos locales en cuanto a promover el éxito económico local sobre la base de pequeñas empresas debidamente compenetradas con el tejido empresarial regional $\mathrm{y}$ nacional.

El término competitividad es normalmente entendido como la capacidad de una empresa para competir, crecer y lograr rentabilidad en una industria o mercado. Esta definición está, sin embargo, asociada al aspecto territorial. Si en un espacio territorial significativo una firma no tiene competidores, entonces tampoco tendrá incentivos para mejorar sus niveles de desempeño y ganar más participación en el mercado.

Aunque la posibilidad descrita es cada vez menos frecuente, no deja de ser perceptible la dificultad al hablar de competitividad a nivel de empresas cuando el mercado no tiene un referente válido para establecer comparaciones. En sectores bajo condiciones oligopólicas o de competencia restringida (aeronáutica, telecomunicaciones, energía, entre otros) se pueden apreciar ejemplos de presencia directa (a través de su infraestructura) de empresas, pero baja posibilidad de establecer comparaciones válidas que permitan al mercado determinar diferencias cualitativas y cuantitativas.

Por lo demás, incluso si una empresa no tiene presencia física directa en un determinado territorio, sus productos pueden ser intercambiados a través de los canales comerciales locales, regionales y nacionales (presencia diseminada).

En cualquiera de los dos casos citados -empresas a gran escala y bajo condiciones de competencia restringida o empresas con presencia directa y/o representación diseminada-, el éxito económico (rentabilidad) puede no ser sostenido si los mercados locales: no consiguen establecer una relación costo-beneficio satisfactoria, no acceden a los productos por un efecto de «alto costo percibido» o por la baja disponibilidad real de estos, o si la dinámica económica de la empresa no tiene incidencia clara sobre la dinámica económica local. Sobre esto último, vale decir que las empresas pueden ser competitivas por sí mismas sin que, necesariamente, la industria, el mercado y, particularmente, el territorio en el que sus productos se diseminan sean competitivos. En consecuencia, debe establecerse una distinción fundamental entre las nociones de competitividad empresarial y competitividad con enfoque territorial.

Al respecto, en su modelo de competitividad de las naciones, Michael Porter ya había destacado la importancia de entender la competitividad en una dimensión territorial (por ejemplo, cuando sostiene que una nación es competitiva si las condiciones de competencia en el mercado doméstico son altas). No obstante, luego de casi 20 años de divulgación de dicho postulado parece haberse olvidado, especialmente en los países en vías de desarrollo, que la verdadera competitividad tiene un anclaje local.

La competitividad puede, finalmente, quedar o no restringida a las empresas o firmas, pero tendrá un impacto profundo en la posibilidad de construir un nivel de competitividad sostenida que beneficie de 
modo balanceado a los actores sociales (el mercado y el capital humano que sustenta la oferta de bienes y servicios) y a los agentes o motores económicos (las empresas) en periodos más o menos largos de tiempo.

Contar con postulados que consigan articular la dimensión puramente empresarial y operativa (medición del desempeño en el corto plazo) con la dimensión territorial y sus actores es, en consecuencia, una natural preocupación para los sectores gubernamentales. Ello en virtud de que el propósito de los gobiernos no está asociado a que las empresas tengan éxito, sino, más bien, a que: dadas condiciones favorables y planificadas en un espacio territorial, las empresas exitosas y/o que crecen puedan tener impacto sobre la calidad de vida y el bienestar de la sociedad inscrita dentro del ámbito territorial de incidencia geopolítica del gobierno, así como de influencia económica de las empresas.

Una noción surgida en los últimos años, que parece incorporar el postulado previo, fue proporcionada ya en 1985 por Scout y Lodge, en el sentido siguiente:

La competitividad es la habilidad de una nación-estado para producir, distribuir y proporcionar bienes y servicios en la economía internacional en competencia con otros bienes y servicios producidos en otros países, y haciéndolo de una manera tal que consiga elevar su nivel de vida (Scout y Lodge, 1985).

No obstante, si el sujeto de análisis es solo la gran empresa, puede ocurrir que el mismo mecanismo que explicó su ingreso en un mercado local (la movilidad de los flujos de inversión) sirva también para entender su presencia sin impacto en la competitividad local. En ese marco, una operación (proyecto privado de inversión) puede estar asociada a los más altos niveles de productividad, calidad, variedad de líneas de productos y precios, sin que ello implique necesariamente una articulación o un anclaje con la economía local.

Un caso extremo ocurre con empresas de envergadura y/o eminente posicionamiento de marca que no quedan restringidas a espacio territorial alguno. La empresa siempre puede hacer uso de los canales de comercialización locales establecidos, sin siquiera tener que invertir en publicidad o merchandising. Todo lo que necesita para extraer valor económico de los espacios locales es un acuerdo comercial con un distribuidor válido, cuyo objetivo también sea apropiarse del valor económico de la economía local.

Menos extremo es el caso de compañías cuyos productos son elaborados localmente pero no son consumidos allí. Como ocurre, por ejemplo, con la producción de espárragos en el departamento de La Libertad. Siendo la demanda local incipiente (no hay tradición de comer espárragos en el Perú) y las oportunidades externas atractivas (Europa, Japón), la actividad desarrolla articulaciones mínimas con las actividades económicas locales (empleo limitado y poco calificado, incipiente nivel de subcontratación local, alto grado de control y propiedad sobre cada aspecto de la cadena productiva, etcétera.). Su impacto en la competitividad y el desarrollo económico local es, por ende, también incipiente.

Los dos casos previos son, desde una perspectiva nacional de gobierno, altamente demostrativos de una buena política de promoción de las inversiones. Empero, desde una perspectiva de fomento al desarrollo local la evaluación podría ser neutra, en el 
mejor de los casos. Ello no significa que no sea conveniente contar con industrias e inversiones de las características citadas en los dos casos previos, sino que ese tipo de inversión juega un papel específico y limitado en la economía y los niveles de bienestar de la sociedad.

No debe, por tanto, aspirarse a que las medidas de fomento a la inversión de escala agregada o nacional logren enfrentar las necesidades y las oportunidades de desarrollo locales. Es fundamental diseñar medidas de fomento económico desde la perspectiva local o endógena, principalmente desde el ámbito de los gobiernos descentralizados, que son los competentes en materia de promover el desarrollo local en sus varias manifestaciones.

Finalmente, resulta evidente que en el plano del anclaje local, la pequeña empresa es el tipo de inversión y emprendimiento que tiene, a escala ampliada, el mayor potencial para desarrollar articulaciones con muchas de las actividades económicas locales, incluyendo aquellas que son insumos obligados en la gran actividad empresarial demandante de subcontratistas locales, preferentemente, y mano de obra altamente calificada, entre otros. La pequeña empresa es, por tanto, el corazón mismo de la competitividad y el desarrollo económico local.

Otra reflexión para los gestores de política es que, según el enfoque presentado, la competitividad deja de ser una habilidad para competir y ganar mercados privativa de las empresas privadas. La competitividad es, más bien, un proceso dinámico que depende del estado actual de una sociedad (incluyendo su territorio), que abarca: las condiciones bajo las cuales los individuos y los emprendimientos locales pueden participar en la producción doméstica o foránea (destinada al mercado doméstico y foráneo); el aporte de las empresas que crecen y son rentables en la creación de riqueza, bienestar y compromiso con el estado de los recursos naturales y del ambiente; las instituciones sociales que participan en las decisiones de priorización del gasto y la inversión social; y un gobierno local que incida positivamente en la orientación de la naturaleza y destino de los ingresos públicos, así como de la reinversión de la rentabilidad privada.

Lo expresado en el párrafo anterior describe lo que probablemente sea uno de los desafíos máximos para los gestores de políticas de desarrollo local, particularmente en países en vías de desarrollo y economías emergentes. La segunda implicancia presentada tiene el propósito de llamar la atención sobre la necesidad de diseñar políticas y estrategias ad hoc para promover el eslabón económico articulador entre las fuerzas de mercado y las fuerzas endógenas del desarrollo: la pequeña empresa.

\subsection{Pequeñas empresas $y$ emprendimientos locales: factores de desarrollo}

La literatura relevante sobre el estrato de las pequeñas empresas las considera piezas clave para la prosperidad local y regional, en virtud de su contribución a: a) la creación de empleo (OECD, 1996); b) el crecimiento económico (OECD, 1997), particularmente si las pequeñas empresas coadyuvan a la mayor participación en el comercio internacional de empresas locales (medianas y grandes) o si ellas mismas inician operaciones de exportación; y c) el impulso a la competitividad local asociada a las innovaciones que dinamizan los mercados de oferta y demanda de factores de producción 
y conocimiento, y que pasan a formar parte de la propiedad intelectual del país (Becker, 2004).

Estrechamente ligado al campo de la pequeña empresa, el emprendimiento también viene recibiendo gran atención en el mundo académico, el sector público e incluso el sector privado debido a que la creación de nuevas empresas, particularmente aquellas que emergen a la luz de nuevos modelos de negocio, contribuyen significativamente al desarrollo económico.

Su capacidad de transformar ideas «singulares» en oportunidades económicas hace de los emprendimientos un medio efectivo para revitalizar el mercado local, regional y eventualmente global, como lo demuestra el encumbramiento de disruptores como Apple y Microsoft, en los años noventa, y los encumbrados Youtube y Google, así como cientos de nuevos ventures, con un enorme potencial como Project Impact, Raydiance, Expensr, Zipcar, Bloom Energy, Second Life y Renewable Energy Group, entre otros, solo en la última década.

Gallo (1996) define al emprendedor como aquel capaz de innovar y de aprovechar cualquier mínima oportunidad para realizar cambios que conduzcan a nuevos productos, nuevos procesos y nuevos mercados; ello implica mucho más que iniciar una nueva empresa, será necesario crear ventanas de oportunidad. Desde esta perspectiva, el individuo que inicia una empresa no necesariamente es un emprendedor si el emprendimiento no está asociado a algún tipo de innovación.

Para el caso concreto de economías en vías de desarrollo, un estudio comprehensivo de la División del Banco Interamericano de Desarrollo para la Pequeña y Mediana
Empresa (Inter-American Development Bank, 2002) analizó la relación positiva entre el nivel de actividad emprendedora y aspectos como: a) el crecimiento económico, b) el incremento en la productividad y c) el rejuvenecimiento de las redes sociales y productivas locales en las últimas dos décadas. En cuanto al tercer aspecto, el ingreso de nuevas firmas a nuevos mercados o a nuevos sectores de actividad coadyuva a identificar cuáles son las industrias en fase de declinación, lo que contribuye a mantener una eficiente asignación de recursos en aquellas actividades económicas más sensibles a la innovación y a las ganancias en productividad y eficiencia operativa.

En materia social, no existe duda alguna de que los nuevos emprendimientos (por ejemplo, en el sector de aplicaciones basadas en la Internet como medio de soporte) se han convertido en la fuente preferida de oportunidades de trabajo para un creciente número de jóvenes, y en una fuente diversa de potenciales subcontratistas para empresas establecidas, principalmente medianas.

Las razones expuestas en materia social y económica vienen asociadas a diversos propósitos de los gobiernos, en virtud del rol promotor y orientador que estos juegan en procesos de desarrollo, particularmente del desarrollo local. Como parte de los procesos de desarrollo, el medio comprende a los emprendimientos locales, mientras que el instrumento abarca el diseño, la implementación y la gestión de políticas orientadas a retroalimentar condiciones para que esos emprendimientos se multipliquen, se consoliden y evolucionen.

Una posibilidad en la mencionada ruta evolutiva es que un emprendimiento individual (o de nivel microempresarial) evolucione hacia una pequeña empresa; luego, 
que esta devenga en mediana empresa o en un conjunto de redes o clusters de pequeñas empresas que compiten y cooperan para desarrollar ventajas competitivas colectivas $\mathrm{y}$, eventualmente, articulaciones de alto valor con sistemas productivos externos.

\subsection{Desarrollo económico en función de la actividad empresarial de la pequeña empresa}

Durante los últimos años, numerosos estudios y abundante evidencia empírica han permitido entender que el emprendimiento y el surgimiento de pequeñas empresas constituyen una fuerza dinámica fundamental para el desarrollo económico local y la competitividad regional, tanto en países desarrollados (Estados Unidos de Norteamérica, Canadá y Japón) como en países en vías de desarrollo y/o de renta media (Perú, Brasil, Chile y México).

La mayoría de los países del mundo mantiene una base estadística, descriptiva en mayor o menor grado, que muestra la contribución de las pequeñas firmas y de los emprendedores a la economía. En el caso del Perú, el Instituto Nacional de Estadística e Informática (INEI) así como varias otras entidades públicas y de investigación están empezando a estudiar más a fondo este aporte. Sin embargo, algunos investigadores locales como Mejía (2002), Roca y Vargas (2002) y Villarán (2000) han apuntado a un aspecto paradójico entre la dimensión macroeconómica y la microeconómica. Mientras en el Perú los niveles de emprendimiento y de contribución a las variables económicas, como el empleo, son iguales o más altos que en Estados Unidos o Japón, las características microeconómicas de la pequeña empresa y los emprendimientos locales son notoriamente distintas.
En ambos grupos de países las contribuciones de la pequeña empresa y de los emprendimientos locales constituyen más del $80 \%$ del empleo total, una elevada participación en el conjunto del tejido empresarial (cerca del 90\% de todas las firmas y 99\% de todas las empresas familiares), un soporte esencial para una amplia porción de la población del país y un aporte al producto bruto de aproximadamente $50 \%$. Inclusive, los índices de mortandad de las pequeñas empresas dentro de los primeros años de operación son similares en Japón, Estados Unidos y Perú.

Ello implica que una lectura macroeconómica nos puede conducir a ideas erróneas, como que a mayor cantidad de pequeñas empresas, mayor progreso de la economía local y nacional. No obstante, la realidad nos muestra que en el Perú cerca del 100\% de los microempresarios desempeñan actividades asociadas a la supervivencia, las cuales les permiten llevar alimento a sus familias. Es claro que la preocupación de los pequeños empresarios en países como Japón está muy lejos de centrarse en la supervivencia.

¿Por qué dos sociedades cuya economía depende en alto grado del dinamismo de sus pequeñas empresas (cerca del 90\% de las unidades económicas, como valor más frecuente a nivel mundial) muestran un desempeño económico tan disímil en sus niveles macroeconómico y microeconómico? La diferencia sustancial entre ambas puede ser explicada, entre otros factores, por lo que Reinert (1996) ha denominado «diferencias en la calidad de las actividades económicas».

En los países desarrollados esta «calidad» está asociada al desarrollo de tecnologías y/o productos disruptivos, así como a 
la habilidad de los nuevos emprendimientos para articular sus innovaciones con los esfuerzos de investigación y desarrollo que despliegan las empresas medianas $\mathrm{y}$, particularmente, grandes. El hecho de que las nuevas empresas que desarrollan tecnologías disruptivas con potencial de mercado sean adquiridas o absorbidas a precios exorbitantes por empresas grandes establecidas permite entender por qué la «calidad» de la actividad económica determina una diferencia sustancial entre una economía y otra.

La discusión preliminar tiene el propósito de reflejar la necesidad de ir más allá de las estadísticas agregadas, como los índices macroeconómicos. Una lectura agregada y genérica (empleo, número de empresas y aporte al PBI) oculta información valiosa sobre la enorme heterogeneidad que subyace en la actividad emprendedora y en los fundamentos que gobiernan a la pequeña empresa en determinados contextos territoriales.

No existe una fórmula universal para promover la competitividad de la pequeña empresa, pero sí criterios orientadores de política que los gobiernos descentralizados pueden emplear para diseñar sus medidas de fomento al desarrollo económico (en los espacios locales y regionales), teniendo en cuenta que las pequeñas empresas tienen mayor oportunidad de fortalecer su nivel de competitividad y desarrollar su potencial innovador desde un anclaje local.

\section{Dos dimensiones de análisis para el diseño de políticas de fomento a la com- petitividad de la pequeña empresa}

En el acápite anterior se discutió sobre algunas de las ventajas de incorporar una lectura local del desarrollo y de identificar por qué los emprendimientos locales -particularmente las pequeñas empresasrequieren ser fomentados desde el ámbito gubernamental y, eventualmente, empresarial.

En esta parte se abordan dos dimensiones de análisis cuyos resultados constituyen criterios de decisión para la formulación de políticas públicas de fomento al desarrollo económico local sobre la base de la competitividad de la pequeña empresa.

También se trata brevemente la dimensión geográfica del desarrollo económico como criterio de partida en el proceso de diseño de políticas de desarrollo económico local sobre la base de la pequeña empresa. Asimismo, se continúa con el análisis de la competitividad de la pequeña empresa innovadora, que conduce a trazar una ruta de éxito en dos niveles: la competitividad externa y la competitividad interna.

Las dos dimensiones de análisis están orientadas a esclarecer la necesidad de diferenciar el diseño de las políticas de fomento a la competitividad de la pequeña empresa $\mathrm{y}$, por ende, a aumentar las probabilidades de éxito de los programas que, mediante el apoyo a este sector empresarial, inciden en el desarrollo económico local y la competitividad territorial.

\subsection{Localización y calidad de la actividad económica de alto valor}

La percepción sobre el papel que juegan las pequeñas empresas en el desarrollo económico de una nación ha variado a lo largo de las últimas décadas. En un importante número de países o economías, el estrato de la pequeña empresa ha sido por largo tiempo visto como una fuente 
de subsistencia para aquellos individuos que no lograban incorporarse al mercado de trabajo. Desde esta primera perspectiva, el tipo de soporte brindado por el sector gubernamental ha sido paternalista.

Por el contrario, en otros países o economías, la pequeña empresa ha sido entendida como una expresión pura del espíritu emprendedor local y como una fuente de oportunidades para el desarrollo económico y social. Desde esta segunda perspectiva, el tipo de soporte brindado por el sector gubernamental ha sido más ambicioso y pro emprendedor. Más aun, ha contado con el concurso de entidades privadas y organizaciones de la sociedad civil.

En un lapso de aproximadamente dos décadas, los hechos han favorecido a quienes adoptaron esta última perspectiva. Las diferencias en el desempeño económico nacional (e incluso entre regiones de un mismo país) han sido, ciertamente, influenciadas por la perspectiva adoptada en cuanto a la postura de fomento del estrato de la pequeña empresa. Los casos más sonados en el mundo han proporcionado la evidencia más clara acerca del valor agregado que las pequeñas empresas con potencial de mercado aportan a las economías locales, regionales $\mathrm{y}$, en última instancia, nacionales.

Es importante destacar que la decisión gubernamental - política pública- de adoptar una perspectiva paternalista o pro emprendedora no es determinante en el éxito económico de la pequeña empresa. Por sus características y restricciones naturales, las pequeñas empresas están íntimamente vinculadas a las características y condiciones de su entorno local inmediato.

Las aglomeraciones (clusters) y efectos colectivos sobre la eficiencia, la producti- vidad y la innovación en una determinada actividad económica dependen, por mucho, de factores geográficos; particularmente de la proximidad física o de la intensidad de los flujos de cooperación interempresarial y/o de intercambio de buenas prácticas y técnicas. Al respecto, son numerosas las investigaciones por consultar, las que abordan la localización como factor crítico para el éxito de los emprendimientos locales (High, 2004; Mccann y Arita, 2004; SuárezVilla, 2004) y la focalización de las políticas de fomento empresarial.

En el caso particular del presente artículo, el tema principal está más vinculado a los tipos de fomento una vez que las consideraciones sobre «localización»se han tomado en cuenta. Sin embargo, cabe destacar la importancia de la localización en el surgimiento de emprendimientos y aglomeraciones empresariales en espacios geográficos específicos, en los países desarrollados o en las economías emergentes. Así, por ejemplo, en Estados Unidos de Norteamérica las industrias de tecnologías de información y software tienen una mayor probabilidad de florecer en los territorios de la costa oeste, como California (Silicon Valley) o Seattle. En Italia (Lombardía), España (Cataluña), China (Shangai), Japón (Kobe) y la India (Bangalore) se pueden señalar que los patrones geográficos tienen alta incidencia en el florecimiento de aglomeraciones de pequeñas empresas con potencial de mercado.

Como elemento adicional para la discusión, es oportuno interrogarse sobre si las pequeñas empresas que desarrollan conexiones fuera de sus territorios -por ejemplo, participando en los circuitos productivo-comerciales que forman parte del comercio global- también pueden florecer y crecer arraigadas a sus espacios locales 
de origen. Es importante destacar que esta posibilidad es poco aplicable en el caso de la gran empresa, dado que los indicadores de evaluación de resultados eventualmente incorporarán el grado de «internacionalización» de la firma como medida de logro.

El hecho de que los casos exitosos de internacionalización de pequeñas empresas hayan tenido lugar, fundamentalmente, en sectores de alta tecnología impide apoyar la creencia de que las políticas óptimas de fomento a la pequeña empresa sean las que promueven los emprendimientos locales en actividades con alto potencial de articulación con los flujos comerciales que emergen al amparo de la globalización.

Por el contrario, se sostiene que la influencia de la globalización sobre los espacios locales involucra una potencial articulación con aquellas pequeñas empresas que muestran altos niveles de competitividad, productividad e innovación, incluso si sus operaciones permanecen arraigadas a su espacio local de origen. Nonaka y Takeuchi (1995) sostienen que esta potencial articulación gira en torno a la disponibilidad de nuevas fuentes de intercambio de conocimiento, tácito y codificado, ligadas a facilidades logísticas (que favorecen el comercio) y tecnológicas, que auspician la formación de redes virtuales de cooperación, las inversiones y el comercio.

En el campo financiero, la globalización comprende la libre movilidad de los flujos de capital a través de las fronteras en busca de altos retornos para las inversiones. El seguimiento a las rutas que siguen las inversiones (Unctad, 2001) ha facilitado la ubicación de los puntos de destino y permite constatar que no se distribuyen homogéneamente en un determinado país o economía.
Asimismo, los destinos más codiciados para los flujos de inversión se concentran no solo en regiones donde existe una concentración empresarial en actividades de alta tecnología, sino también en regiones donde las capacidades técnicas y el potencial de innovación son significativos. Esta evidencia permite identificar una ventana de oportunidad para pequeñas empresas que, a falta de mayor especialización en actividades de alta tecnología, se caractericen por su potencial de generar innovaciones.

Más aun, si las pequeñas empresas desarrollan ventajas competitivas distintivas en cuanto a innovación de productos, procesos eficientes y desarrollo de técnicas creativas, su probabilidad de generar conexiones con los flujos de inversión globales aumenta. De ser así, se evidenciaría una de las afirmaciones de vanguardia en cuanto a entender a las pequeñas empresas como canales de difusión de innovaciones y agentes de mercado flexibles, las cuales pueden adoptar ágilmente tecnologías y procesos que tienen un papel esencial en los flujos productivos y comerciales, regionales y globales.

Una primera implicancia para gestores de políticas en países en vías de desarrollo la constituye el hecho de que la promoción de la pequeña empresa de manera agregada a nivel nacional no explota las ventajas potenciales de la localización. Incluso, es posible que una intervención de índole eminentemente macro contribuya a reforzar la estructura productiva basada en actividades económicas de escaso valor agregado, como las materias primas o la manufactura de baja complejidad (concerniente al estrato de la pequeña empresa).

Las decisiones centralizadas a nivel del gobierno nacional, por ejemplo, tienden a generar una lectura de país (asociada a 
ventajas nacionales) que puede obviar las diversas oportunidades que emergen en los espacios locales. Una posición política de esta índole genera información crítica valorada por inversores que buscan ventajas comparativas, nacionales o regionales, como la dotación de recursos naturales, el tamaño de los principales mercados metropolitanos de consumo, la disponibilidad de mano de obra barata o la cercanía del país receptor a mercados más atractivos en virtud de acuerdos comerciales preexistentes o de inminente concertación.

Una segunda implicancia alude al hecho de que la eficaz promoción del desarrollo económico local sobre la base de la pequeña empresa es una función que depende del desarrollo de innovaciones locales o de la permeabilidad de los sistemas productivos locales para absorber y adaptar nuevas tecnologías, que fomenten un renovado nivel de competitividad en determinadas actividades económicas localizadas.

Si las intervenciones gubernamentales a favor del desarrollo económico local no contemplan los aspectos de innovación y modernización de los sistemas productivos locales, las oportunidades de conexión con flujos externos de inversión pueden tornarse inviables; ello en virtud de una brecha de capacidades (por ejemplo, carencia de mano de obra altamente calificada y de flexibilidad en los procesos para facilitar la subcontratación de pequeñas empresas) que impide la articulación entre la inversión, las oportunidades y el sistema productivo local.

En el campo del comercio, la globalización alude a la libre movilidad de bienes y servicios a gran escala, tanto de materias que sirven de recursos a los procesos de manufactura como, cada vez más, de bienes y servicios intensivos en conocimiento. En países primario-exportadores como el Perú (las exportaciones mineras explican más del $40 \%$ de las exportaciones totales, pero solo cerca del $20 \%$ del PBI), la dimensión comercial internacional solo coincide con la oferta a gran escala en cuanto a exportaciones primarias, mas no con la tendencia que privilegia bienes intensivos en conocimiento.

Esto quiere decir que las oportunidades del comercio global solo favorecen a un pequeño grupo de grandes corporaciones, que tienen la capacidad y los medios para explotar los recursos naturales; mientras que el resto de las pequeñas unidades económicas ven limitadas sus posibilidades de lograr conexiones que les permitan ofrecer sus productos o servicios fuera de las fronteras nacionales. Esta restricción se debe a que las pequeñas empresas no poseen la escala de operaciones que, por ejemplo, es un factor crítico en la industria minera. Tampoco poseen la tecnología ni el expertise para producir una oferta de bienes y servicios intensivos en conocimiento, con potencial de competir en la arena global.

Una tercera implicancia para los gestores de política responde al imperativo de cambiar de paradigmas, es decir, pasar de un enfoque arraigado en las ventajas comparativas nacionales derivadas de la posesión de recursos básicos a otro en el que la diversificación económica y la innovación tengan lugar en el ámbito local. Asimismo, dejar de lado la perspectiva según la cual la inversión productiva de alto valor depende solo de las inversiones a gran escala, para impulsar aquella en la cual las pequeñas empresas y los emprendedores locales cuenten con las condiciones y las capacidades para participar en la transformación de los sistemas productivos locales en un esquema de mayor valor agregado. 
Las tres implicancias presentadas ya forman parte de la agenda de debate en un gran número de países y economías. No obstante, en algunos países en vías de desarrollo se presentan cuellos de botella al momento de buscar consenso acerca de si las políticas económicas adoptadas a partir del ámbito nacional de gobierno han tenido éxito no solo en el nivel macroeconómico (estabilidad fiscal, control de la inflación, incentivos fiscales a la inversión, gasto público en provisión de infraestructura vial), sino también en el nivel microeconómico (fomento de las economías locales, con énfasis en la especialización territorial, la innovación y la sostenibilidad del crecimiento)

\subsection{La ruta de éxito de los emprendedores innovadores: repositorio de conocimiento al alcance de los gestores de políticas de competitividad y desarrollo económico local}

Esta segunda dimensión de análisis se concentra en describir, particularmente para el caso de países en vías de desarrollo y economías emergentes, una ruta de éxito trazada por un tipo particular de emprendedor, cuyo perfil fue identificado en dos estudios exploratorios preliminares conducidos entre los años 2001 y 2004.

El primer estudio, que empleó como instrumento de partida el método de casos (Audet and d'Amoise, 1998), permitió identificar pequeñas empresas que han obtenido un posicionamiento distintivo (buenos negocios) en su sector económico y crecimiento sostenido (con características de mediana empresa) en un lapso corto y sin mayor soporte estatal.

El segundo estudio (Vargas, 2004b) permitió identificar un grupo de empresas que, bajo idénticas características de control (incluyendo la elección del distrito o espacio local para el estudio), mostraban patrones similares de comportamiento competitivo y desempeño en dos campos: en cuanto a los resultados del negocio y en lo relacionado con la naturaleza de los aportes y/o contribuciones al desarrollo local (articulaciones con otras actividades presentes en la economía, evolución en la calidad del empleo ofrecido y clima laboral, entre otros).

En los que se refiere a las características de control, se consideraron las siguientes:

a) Anclaje local: las firmas analizadas se encontraban operativamente localizadas en un determinado espacio de demarcación geopolítica (distrito). Se eligió el conglomerado industrial de pequeñas y microempresas del distrito de Villa El Salvador, localizado a 15 kilómetros al sur de Lima. En este conglomerado se ha mantenido, durante aproximadamente veinte años, una presencia mayoritaria de empresas surgidas de emprendimientos endógenos.

b Antigüedad: las firmas datan de similar fecha de creación. Se tomó en cuenta esta característica con la finalidad de poder comparar las trayectorias empresariales.

c) Factor generacional: el miembro fundador continúa al frente del negocio familiar. Este dato permitió concentrarnos en los eventos clave que tuvieron lugar en la génesis de la firma.

d) Carácter innovador: las firmas debían desarrollar innovaciones (nuevos procesos, nuevos productos, nuevos tipos de mercado, nuevos clientes, nuevas políticas de gestión, principalmente) 
con regularidad. Ello garantizaría que el estudio comprendiese exclusivamente a individuos emprendedores.

e) Vinculaciones ganar-ganar: los emprendedores disfrutan de amplio reconocimiento entre el público empresarial local, los vecinos y las autoridades públicas. Ello permitió explorar si el éxito de los emprendedores tenía influencia en las condiciones de desarrollo local, bienestar de la comunidad y difusión de buenas prácticas entre la comunidad de negocios local.

Los hallazgos obtenidos conducen al siguiente postulado: Es favorable para la economía local contar con emprendedores innovadores, pero es más favorable contar con una masa crítica de emprendedores de corte innovador.

Consecuentemente, una forma de interrumpir localizadamente el ciclo de pobreza y subdesarrollo que afecta a los espacios locales en países en vías de desarrollo consiste en capitalizar el conocimiento con relación a la fórmula creadora o ruta de éxito de los emprendedores innovadores. El empleo de dicho conocimiento, se sostiene, permitiría diseñar políticas públicas desde el nivel local de gobierno para fomentar el surgimiento y el crecimiento de unidades económicas que incidan favorablemente en la competitividad, el desarrollo económico local y la calidad de vida, incluso si el clima económico nacional es adverso.

En este marco, esta segunda dimensión de análisis se deriva de la sistematización de los componentes específicos que invitan a transitar por la ruta de éxito de los emprendedores innovadores. Se sostiene, asimismo, que las políticas de fomento a la pequeña empresa tienden a ser más sos- tenibles e impactantes si los factores que las sustentan reflejan apropiadamente las condiciones locales en materia económica, social y política.

De este modo, se presentan los factores de éxito de la ruta de competitividad de los emprendedores innovadores, los que sirven de soporte a la competitividad sostenida de la pequeña empresa sobre la base de esfuerzos endógenos y medidas de fomento complementarias desde los sectores gubernamental (actor primordial) y no gubernamental (cooperación técnica y empresas privadas). Por ende, se postula que: Las pequeñas empresas competitivas y con un compromiso genuino a favor del desarrollo no dependen (o dependen en menor grado) de programas externos de fomento -como los gubernamentales o de cooperación técnica que incluyen infraestructura productiva, información de mercados, bonos, asistencia técnica, entre otros-para mejorar de modo sostenido sus niveles de productividad y competitividad.

\subsection{Factores de éxito para la competitividad de la pequeña empresa}

Los factores de éxito a los que se hace referencia constituyen un conjunto de once prácticas de gestión que permiten obtener un nivel mínimo eficiente de estabilidad en la marcha del negocio y que, de modo progresivo, contribuyen a crear capacidades y comportamientos organizacionales que son esenciales para movilizar el potencial de crecimiento y competitividad endógeno de la empresa.

La adopción de estas prácticas no garantiza la obtención de ventaja competitiva sostenida, pero brinda un conjunto de medidas de desempeño que permiten monito- 
rear y evaluar el grado en que una empresa (pequeña o microempresa) ha iniciado y avanza dentro de la ruta de éxito de la empresa innovadora.

Los gestores de políticas pueden tomar los aspectos que a continuación se desarrollan como guías para diseñar intervenciones o medidas de fomento a la competitividad de la pequeña empresa. Una práctica en particular contempla elaborar e incorporar compromisos y/o metas de logro aplicables a las empresas beneficiarias de programas gubernamentales y no gubernamentales de fomento a la competitividad de la pequeña y microempresa.

\section{Práctica 1: Diversificación y liquidez}

A fin de resistir las fluctuaciones del mercado, especialmente en cuanto a la inestabilidad de las ventas y la captura de opciones de crecimiento en el mercado, los emprendedores pueden impulsar nuevas categorías de productos cuya demanda individual siga un comportamiento anticíclico con relación a las otras líneas de producto.

La evidencia encontrada muestra vínculos de cooperación cuyo objetivo es un aprendizaje mutuo acerca de los procesos de manufactura de productos de alta demanda y relativamente estandarizados, como calzado, muebles de madera y metálicos, confecciones y alimentos (productos lácteos y golosinas, por ejemplo).

Las nuevas fuentes de ingreso resultantes permiten mantener un nivel de ventas relativamente homogéneo a lo largo del periodo (algo inusual en el ámbito de la pequeña empresa y, en particular, de aquella que produce bajo demanda). En consecuencia, se evitan la capacidad ociosa y la falta de liquidez, lo que posibilita la acumulación de capital y la reinversión -clave para financiar el desarrollo innovador de las líneas de producto core-.

\section{Práctica 2: División del trabajo}

Se identificaron ganancias significativas en productividad derivadas de los efectos positivos de dividir el trabajo en actividades parciales y especializadas, lo que permite hacer un óptimo uso de los recursos y de las destrezas de los trabajadores. Así, por ejemplo, se encontró que los trabajadores que se especializaban en tareas clave del proceso productivo aportaban regularmente al ajuste de los procesos y a la reducción de las fallas de calidad.

Por otro lado, se identificó que el rol del gestor del negocio (el emprendedor) también varía en la medida en que la empresa madura. De una atención prioritaria a los aspectos meramente productivos, deriva hacia una atención cada vez mayor a los componentes de la gestión del negocio, la lectura de las tendencias del mercado, el control de calidad, la satisfacción del cliente y la construcción de visiones y estrategias para el futuro.

\section{Práctica 3: Gestión responsable del capital humano}

A efectos de estimular la identificación de los operarios y/o trabajadores con los objetivos de la empresa (visión compartida y trabajo en equipo) y de facilitar la transferencia de conocimiento de los operarios más experimentados hacia los operarios que aún se encuentran en fase de entrenamiento, se implementan medidas explícitas para mantener la motivación y la moral.

El diseño de paquetes de incentivos (no necesariamente contemplados en la 
legislación laboral vigente para la pequeña empresa), de reconocimientos públicos al buen desempeño, así como de premios a la innovación y/o la mejora de los procesos y a la calidad y la satisfacción del cliente son frecuentes en las pequeñas empresas emprendedoras y exitosas.

\section{Práctica 4: Compras consolidadas y puntualidad con los proveedores}

Se halló evidencia abundante con relación a las compras de insumos y materiales clave para el proceso productivo concentradas en pocos proveedores de alta confiabilidad y conformidad con las condiciones del insumo o material proveído. El aspecto saltante es que las carteras de proveedores de los productores más exitosos son muy similares, lo cual se debe al cruce de información entre productores.

Adicionalmente, los buenos referentes, en cuanto al cumplimiento estricto en las condiciones de crédito que brinda el proveedor, surten el mismo efecto que las tecnologías de garantía solidaria de pago puntual empleadas en la actividad microcrediticia. Los productores que comparten una cartera similar de proveedores concuerdan políticas estrictas de cumplimiento de pago con los proveedores que forman parte de los códigos de responsabilidad en la gestión. El impacto de esta buena práctica es la facilidad para acceder a compras consolidadas y descuentos importantes en el costo de los insumos y materiales (lo que es frecuente en la mediana y gran empresa, pero no en la pequeña empresa), algunas veces con tasas de interés simbólicas.

Esta facilidad de acceso al crédito del proveedor genera ahorros importantes y evita que las pequeñas empresas se vean obligadas a solicitar costosas líneas de capital de trabajo a las entidades del sistema financiero.

\section{Práctica 5: Innovación de productos y procesos}

La innovación es el principal elemento de coincidencia en la gestión y operación de las pequeñas empresas innovadoras. Esta cualidad debe analizarse desde dos perspectivas.

La primera consiste en destacar la dificultad de introducir innovaciones en los procesos y en los productos que no hayan sido antes implementadas por empresas consolidadas y/o de gran tamaño, pues ello implica creación de conocimiento (Rutten y Boekema, 2004).

La innovación es, en este sentido, la resultante de un proceso de aprendizaje por el cual las empresas crean y absorben nuevo conocimiento que es incorporado a sus productos y procesos. Este nuevo conocimiento no es solo sobre tecnología, sino que abarca también el conocimiento de las preferencias del consumidor, las tendencias de la moda, las preocupaciones sobre los daños al medio ambiente, entre otros factores.

La segunda perspectiva destaca la habilidad de los empresarios innovadores, que al ser capaces de poner en valor el nuevo conocimiento que poseen, lo traducen también en términos de mayores precios de los bienes y servicios que ofrecen. En el aspecto gerencial, esta oportunidad viene asociada con el desarrollo de nuevas destrezas para la negociación y el diseño de estrategias para tomar ventaja de una posición de privilegio en cuanto a producir bienes y servicios exclusivos. 
Práctica 6: Creación de alianzas estratégicas con los clientes

El manejo de la cartera de clientes en la pequeña empresa innovadora refleja dos características importantes: a) los clientes son de dos tipos: un creciente número de clientes medianos y un número progresivamente mayor (pero a menor ritmo) de clientes corporativos (grandes empresas) y b) existe una relación de confianza entre los clientes corporativos y las pequeñas empresas que los proveen de productos intermedios (insumos) y terminados.

La importancia de estas características para el desarrollo económico local radica en el hecho de que las pequeñas empresas innovadoras construyen alianzas y conexiones con actores económicos externos al sistema productivo local. Ello abre nuevas oportunidades para que otras pequeñas empresas puedan intentar generar negocios con empresas que ya tienen negocios y vínculos de confianza duraderos con las empresas pioneras.

\section{Práctica 7: Liderazgo interno y participación en redes de cooperación}

Los emprendedores innovadores invierten recursos, tiempo y esfuerzos en inspirar a otros individuos dentro de la empresa, con una clara visión compartida de «excelente producto, excelente servicio, satisfacción total del cliente y excelente clima de trabajo».

Asimismo, la demostración de cualidades de liderazgo amplio (como parte de un sector industrial o actividad económica) es esencial para demostrar visibilidad en el mercado, así como en la comunidad empresarial y en los espacios sociales relevantes. Los emprendedores innovadores tienden a participar activamente en iniciativas empresariales y sociales, así como a integrarse en estructuras organizativas formales, como consorcios y redes de contactos que les brindan oportunidades de visibilidad y desarrollo de sinergias.

\section{Práctica 8: Creación de barreras de entrada a través de la diferenciación}

Las pequeñas empresas manufactureras normalmente se encuentran restringidas a la producción de bienes sensibles al precio. Los esfuerzos por brindar un valor agregado adicional al cliente (y así forzar la demanda a su favor) son altos y no pueden ser equiparados por los competidores sin que estos, a su vez, incurran en mayores costos. Sin embargo, las empresas innovadoras ya tienen ganado un proceso de innovación permanente y de valores agregados que son apreciados por sus clientes sin que ello implique, necesariamente, mayores costos.

Cuando los competidores procuran asimilar los cambios provocados por el emprendedor es tarde, pues este ya ha construido una oferta que resulta de combinar nuevos productos con servicios de valor agregado que el competidor no tiene tiempo de equiparar.

Una estrategia de diferenciación crea barreras de entrada en un estrato atípico, pues en el segmento de la pequeña y microempresa las barreras de entrada son normalmente bajas y en algunos casos inexistentes.

\section{Práctica 9: Especialización y curva de aprendizaje}

Con relación a la capacitación y/o entrenamiento formal de los emprendedores inno- 
vadores, se halló evidencia abundante que demuestra un alto compromiso por adquirir capacidades técnicas de alta especialización que faciliten la implementación de nuevas estrategias y procesos mejorados. Asimismo, se detectó que las necesidades de capacitación se amplían conforme madura la empresa.

Mientras los temas de capacitación inicial se concentran en aspectos técnicos y en métodos de manufactura, con el tiempo empiezan a cobrar relevancia aspectos de gestión (mercadeo, ventas, recursos humanos, planificación estratégica), de organización (cultura, códigos de conducta, valores) $\mathrm{y}$, eventualmente, temas que tienen que ver con una visión de la empresa vinculada a su entorno local y a los entornos nacional e internacional.

Lo anterior sugiere que los emprendedores innovadores tienden a mejorar sus capacidades y destrezas en la medida en que la empresa crece o se prepara para crecer y/o experimentar cambios cualitativos sustanciales. En este sentido, incluso se detectó -en el caso de la pequeña pero no de la microempresa- que la política y su incidencia en las oportunidades para tentar la internacionalización de la organización eran temas de agenda en la gestión de empresas innovadoras.

Un aspecto interesante que debe resaltarse es la progresiva adopción y uso de políticas de ascensos y de crecimiento técnico-profesional dentro de la empresa. Esta trayectoria se aprecia en dos fases:

a) Mientras la empresa consolida capacidades productivas y de estabilidad en la buena gestión, los operarios son entrenados intensivamente en aspectos técnicos. b) En la medida en que el líder de la empresa (el emprendedor) asume nuevos retos gerenciales (negociaciones, planificación, prospección de mercados) se hace necesario que los operarios más hábiles asuman roles de entrenadores (con aprendices bajo su supervisión) y de protectores de la calidad en los procesos y los productos.

\section{Práctica 10: Flexibilidad y articulación hacia atrás}

La demanda es incierta y, en muchos casos, volátil en el estrato de la pequeña y microempresa. Ello dificulta la planificación de los niveles de producción y afecta la inversión, tanto en el desarrollo de nuevos productos como en la investigación de mercados y de tendencias en patrones de consumo y de preferencias de los clientes. El problema que surge es la pérdida de capacidad de respuesta ante pedidos no planificados (la mayoría) y la dificultad para adecuar los procesos ante cambios importantes en las preferencias del mercado.

Frente a esta coyuntura, las empresas innovadoras emplean determinadas estrategias para ganar flexibilidad y, en consecuencia, recuperar capacidad de respuesta. Así, por ejemplo, se han detectado las siguientes medidas:

a) Aprovechar las redes de cooperación nuevas o existentes para tercerizar parte de la producción.

b) Retener y capacitar permanentemente a los mejores trabajadores.

c) Reasignar los equipos y al personal de líneas de producción temporalmente inoperativas (debido a la baja demanda o a la eventual falta de ella) a otras líneas 
de trabajo o a actividades de mantenimiento y calibración de maquinaria y procesos, así como al desarrollo de nuevos modelos o nuevos productos. El entrenamiento cruzado permite que los operarios puedan desempeñar tareas distintas a las que normalmente tienen a su cargo.

d) Trabajar con celdas de producción virtuales, conformadas por operarios contratados (freelancers) para pedidos y periodos específicos.

Esta capacidad de expandir y contraer sus operaciones en función de la actividad productiva asociada a la demanda del mercado brinda a la empresa alta flexibilidad y capacidad de respuesta, sin sacrificar la estabilidad presente y futura del negocio.

\section{Práctica 11: Lealtad con el cliente y} market share

La pequeña y microempresa en países en vías de desarrollo como el Perú se inicia, por lo general, en respuesta a la necesidad. Las ideas y visiones de los fundadores constituyen un valor agregado que alimenta la posibilidad de que el negocio pase de ser un medio de subsistencia a ser un mecanismo para generar oportunidades de mercado y de desarrollo humano y autorrealización, desde la perspectiva de los fundadores.

El argumento anterior tiene el propósito de explorar qué tipo de motivaciones de los pequeños empresarios incidirían en adoptar una cultura de lealtad hacia el cliente y de búsqueda de su satisfacción, o en optar por un pragmatismo excesivo que pretenda crecer en ventas sin que ello implique generar «clientes».
Si la segunda opción es la que prima, entonces es razonable suponer que los esfuerzos y recursos destinados por la firma a la calidad, la innovación, los servicios de valor agregado y la confianza no serán importantes. Esta segunda opción podrá seguir siendo válida para un contexto de mercados masivos en los que tiene sentido llevar el proceso producción-consumo de modo impersonal, pero es absolutamente ineficiente en mercados donde la diferenciación de los productos, la innovación y las necesidades particulares de los clientes son, entre otros, los criterios que determinan el nexo producción-consumo.

De acuerdo con la evidencia hallada, en las empresas innovadoras que manifiestan una evolución positiva y sostenida en su crecimiento y en el empleo de buenas prácticas (principalmente las diez prácticas presentadas antes), la satisfacción del cliente y la construcción de vínculos de confianza, lealtad y cooperación duraderos constituyen el corazón de la cultura organizacional.

Si los vínculos con los clientes son excelentes, entonces estos, a su vez, brindarán las mejores referencias (nuevos negocios con nuevos clientes o clientes de los competidores) y serán proclives a incluir a la empresa dentro de su cartera de proveedores confiables (más negocio con los clientes actuales). Ambos efectos combinados tienen un enorme impacto en la marcha del negocio (la estabilidad en los niveles de venta y producción) y en las perspectivas del mismo (posicionamiento y reconocimientos), que incluye también una participación superior en el mercado que, eventualmente, generará incentivos para que la empresa busque desarrollar negocios con sistemas de producción-consumo externos (a escala nacional $\mathrm{y}$, eventualmente, internacional). 


\section{Políticas de fomento a la competitividad de la pequeña empresa, con incidencia en el desarrollo económico local}

En sus primeras dos partes, el presente artículo buscó contribuir a ganar un mayor entendimiento acerca de los factores que influyen en el éxito económico y la competitividad de pequeñas empresas con anclaje local y, al mismo tiempo, conexiones externas con otros sistemas productivos y/o clientes corporativos que contribuyen a dar sostenibilidad a su crecimiento e impulso emprendedor.

Se puso, asimismo, especial énfasis en elementos que componen la trayectoria de éxito empresarial que caracteriza a las empresas y empresarios emprendedores, y se postuló que es posible diseñar políticas de fomento a la competitividad de la pequeña empresa, que capitalicen los aprendizajes de las empresas exitosas a favor del desarrollo económico local y la competitividad territorial.

A fin de abordar los lineamientos para diseñar políticas de fomento a la competitividad de las pequeñas empresas bajo condiciones reales, en esta tercera parte del artículo se incorpora un tercer criterio o dimensión relevante de análisis: el ciclo de vida de la empresa. Esta dimensión de análisis conduce a criterios que permiten un mayor entendimiento acerca de cuándo y cómo los emprendedores innovadores consiguen flexibilizar el ciclo de vida de sus empresas, con el fin de propulsar su crecimiento y competitividad.

Para efectos del diseño de políticas de fomento, es posible determinar en qué etapa del ciclo de vida de la pequeña empresa (incluyendo su génesis como microempresa) ciertas medidas tendrán un mayor impacto en su crecimiento y en la reducción del lapso entre el estado actual y la siguiente etapa de crecimiento (por ejemplo, de microempresa a pequeña empresa y de pequeña empresa a mediana empresa).

\subsection{Políticas explícitas de fomento a la competitividad de la pequeña empresa}

En países con procesos de descentralización y transferencia de competencias (como el desarrollo económico local) en marcha es vital contar con políticas. Estas permiten tener claro los propósitos de una intervención, los públicos beneficiarios y aliados, los objetivos o resultados esperados, los indicadores que hagan posible monitorear el resultado o impacto, y las estrategias y las capacidades requeridas. De lo contrario, existe un riesgo imponderable: que los gobiernos descentralizados se vean tentados a replicar experiencias y/o fórmulas que no necesariamente se ajustarán a sus realidades locales, con consecuencias que van desde la insostenibilidad de la intervención hasta una incidencia más negativa que el problema que se intentaba resolver.

En un país como el Perú, donde el proceso de descentralización es reciente, los resultados a la vista sugieren que los programas y las iniciativas de los gobiernos descentralizados aún no consiguen diseñar e implementar propuestas de significancia en cuanto a la promoción del desarrollo económico local y/o al fomento de los emprendimientos locales. A ello se suman las restricciones presupuestales y la carencia de modelos para impulsar los motores de crecimiento endógenos, como la microempresa $y$, particularmente, la pequeña empresa. 
En este contexto, las intervenciones más destacadas resultan siendo aquellas impulsadas desde el gobierno central en periodos previos al inicio del proceso de descentralización. Sin embargo, estas intervenciones, de corte paternalista por lo general, no han demostrado su eficacia en cuanto a lograr que las pequeñas empresas incrementen significativa y sostenidamente sus niveles de productividad, competitividad y grado de articulación con otras actividades económicas locales o con sistemas productivos externos.

Es así que los aportes del presente artículo (anclaje local y, principalmente, la ruta de éxito de los emprendedores innovadores) pueden contribuir a diseñar políticas de fomento en el ámbito de la pequeña y microempresa, como medio para incidir en la competitividad territorial, la calidad de vida y el desarrollo económico local. Un impacto esperado consiste en aprender del éxito de los emprendedores innovadores y diseñar medidas de fomento para multiplicar el número de empresarios y empresas que consigan mejorar sus resultados de negocio, al mismo tiempo que contribuyan al bienestar y a la creación de oportunidades en su espacio local de influencia.

No obstante, aún falta un criterio que complemente a los dos anteriores (de localización y de los factores de éxito), que está asociado al momento o estado de madurez de la empresa, también denominado «ciclo de vida de la pequeña empresa».

\subsection{El ciclo de vida de la pequeña empresa}

Las pequeñas empresas también siguen un ciclo (conocido como el proceso emprendedor). Pueden iniciarse como pequeñas, pero también pueden ser el estado evolutivo de un emprendimiento individual que logró superar las barreras y restricciones de tamaño que caracterizan a la microempresa.

Eventualmente, la pequeña empresa crece hasta enfrentar las barreras y restricciones asociadas a la transición a la mediana empresa o a la competencia dispar con firmas que poseen una mayor curva de aprendizaje. En unos casos la transición ocurrirá en el mediano plazo, mientras que en otros las firmas permanecerán pequeñas o perecerán.

Recientes investigaciones han derivado en distintas aproximaciones para explorar la dinámica del proceso emprendedor. Una de estas aproximaciones sostiene que las pequeñas empresas atraviesan por tres fases:

a) Inception (inicio): es el momento en que la motivación para llevar adelante un emprendimiento se pone de manifiesto, así como la identificación del mercado y el producto al que dirigirá su oferta.

b) Start-up (arranque): aquí el emprendedor toma decisiones tales como iniciar la empresa y prever los mecanismos de obtención de fondos (financiación) y de recursos tangibles e intangibles.

c) Early development (desarrollo temprano): este periodo suele abarcar los primeros años de vida de la firma. En este se manifiestan los factores y las decisiones que condicionan la entrada al mercado, las capacidades operativas y de gestión, así como los desafíos del día a día.

Esta aproximación no contempla los eventos que siguen a una fase temprana de desarrollo y asume que la firma sobrevivirá mientras el mercado continúe demandando 
sus productos. En economías desarrolladas, esta primera aproximación es apropiada, pues los índices de emprendimiento (startup) y de mortandad (failure) sirven para medir el clima de emprendimiento asociado a la supervivencia del más hábil y a la extinción del menos creativo.

En economías en vías de desarrollo, por el contrario, el empleo de esta aproximación podría no reflejar el hecho de que, para sobrevivir, los emprendedores procuran mantener su negocio en operación, incluso si trabajan a pérdida durante un tiempo, en virtud de que este constituye su único o principal medio de subsistencia. Al concentrarse esta aproximación en los primeros años de vida de la firma, restringe la posibilidad de efectuar un seguimiento a los progresos o restricciones asociados a una eventual implementación de la ruta creativa de la pequeña empresa.

Una segunda aproximación alude al aspecto evolutivo de la firma, propugnado por los estudiosos del modelo de empresas familiares (Gallo, 1998). De acuerdo con esta aproximación, se han identificado tres puntos de inflexión que determinan al menos tres estadios de evolución.

En el primer estadio, la empresa es liderada fundamentalmente por el fundador, lo que constituye la primera generación. En la segunda fase (segunda generación), nuevos miembros de la familia del fundador se incorporan a la empresa. Finalmente, en la tercera fase (tercera generación), nuevos miembros (principalmente profesionales) que no son parte de la familia del fundador se incorporan a la empresa y ocupan posiciones de decisión y gerencia.

En esta última fase surgen los denominados «desafíos en la sucesión», nuevos riesgos para el negocio asociados a las decisiones de cómo gerenciar la firma, cuándo y cuánto crecer, así como oportunidades para revitalizarla y diversificar las actividades económicas primigenias.

Gallo plantea que en la primera generación la motivación del fundador está más ligada a la necesidad de subsistir, acumular cierto nivel de capital y mejorar la calidad de vida de los miembros de su familia. Un riesgo importante emerge en la medida en que, durante la primera generación, el fundador no prevea un plan de retiro y de incorporación profesional de los miembros de su familia (fundamentalmente sus hijos), ni nuevos planes para revitalizar la firma. $\mathrm{Si}$ este riesgo se convierte en realidad, es altamente probable que la firma deje de crecer y se mantenga, en el mejor de los casos, en el estadio de pequeña empresa, siendo que su incidencia en la economía local disminuye.

En la segunda y tercera generación, los principales desafíos se trasladan al campo de la gerencia de la firma. Se hacen necesarias nuevas prácticas de gestión y el moldeo de una cultura organizacional que favorezca el cambio, el emprendimiento interno, los valores y visiones compartidos y un alto énfasis en el trabajo de equipo y el control de la gestión. Un riesgo importante emerge en la medida en que las decisiones para revitalizar la firma colisionen con las preferencias de los miembros de la familia del fundador y su esfuerzo por mantener el control de la firma y el acceso preferente a las utilidades. Si este riesgo se convierte en realidad, es altamente probable que la decisión de intentar nuevos emprendimientos (como la diversificación de las líneas de productos, la internacionalización, la modernización, entre otros) se vea restringida y que emerja un alto nivel de conflicto 
entre la familia del fundador y los miembros que ingresaron a la firma en posiciones de decisión.

Esta segunda aproximación aporta en el sentido de discriminar las características particulares de una empresa en virtud de diferencias generacionales que determinan riesgos, oportunidades y decisiones en el futuro. No obstante, esta aproximación no permite explorar el grado en el que la firma se transforma y evoluciona en virtud de los que explican la ruta de crecimiento, innovación y éxito que se ha observado en las pequeñas empresas innovadoras estudiadas.

\subsection{Marco de referencia para el diseño de políticas}

Luego de revisar los dos enfoques o aproximaciones previos, surgen varias reflexiones con relación a si los aspectos asociados al ciclo de vida de la pequeña empresa deberían contemplarse en el diseño de políticas de fomento.

En primer lugar, los enfoques presentados ilustran las diferencias en las decisiones empresariales y en los tipos de riesgos que emergen de modo particular para cada fase de la vida de la empresa, pero no permiten aumentar la comprensión acerca de la incidencia de la innovación y el aprovechamiento del potencial endógeno de la firma como motor de crecimiento empresarial, con un nivel de impacto importante en el desarrollo económico local, en el rejuvenecimiento del sistema productivo local y en la generación de conexiones con sistemas productivos y/o comerciales externos.

En segundo lugar, los enfoques expuestos alertan sobre la importancia de consi- derar que las pequeñas empresas no son homogéneas entre sí, sino que, más bien, son distintas en virtud del resultado de las decisiones asociadas a la gestión y la elección del mix producto-precio-mercado. No incorporan, sin embargo, los factores de éxito en las decisiones estratégicas y en las prácticas de gestión que se basan en la heterogeneidad interfirma, para alentar el surgimiento de una amplia gama de posibilidades de crecimiento y posicionamiento distinto en los sectores de actividad económico-empresarial de las firmas.

En tercer lugar, los enfoques vigentes no parecen prestar atención a la posibilidad de que incluso empresas con características homogéneas (que comparten el mismo sector de actividad, el mismo producto, el mismo proceso, el mismo régimen laboral, etcétera) puedan comportarse de modo distinto en cuanto a su capacidad para alterar el curso regular de su ciclo de vida.

Al respecto, la evidencia hallada en empresas innovadoras sugiere que un indicador global de éxito se refleja en ciclos de vida más cortos, que impulsan a la empresa hacia el siguiente nivel de actividad en función del tamaño, vale decir, de microempresa a pequeña empresa y de pequeña a mediana empresa.

En cuarto lugar, y ya en el campo de la competencia gubernamental de promover el desarrollo local, las pequeñas empresas constituyen medios potencialmente efectivos para promover el desarrollo económico y la calidad de vida en un espacio local. Dicho potencial, sin embargo, queda restringido si los rendimientos de la firma solamente responden a las necesidades de subsistencia y a las preferencias de gasto e inversión de sus fundadores. 
A menos que se trate de una postura política de corte asistencialista, la posibilidad descrita colisiona con la misión de los gobiernos descentralizados en cuanto a diseñar medidas de política y asignar recursos públicos a programas de fomento a la pequeña y microempresa. Consecuentemente, los gobiernos descentralizados deben tomar previsiones para garantizar que las medidas de fomento no se concentren en firmas que no tienen un impacto real y positivo neto sobre la calidad de la actividad económica local ni sobre la creación de oportunidades de bienestar y desarrollo humano.

En este sentido, una forma de garantizar que las medidas de fomento tengan un nivel significativo de incidencia es hacer uso del conocimiento generado por los fundadores y gestores de pequeñas empresas innovadoras que han logrado establecer con éxito conexiones de negocio con sistemas productivos y comerciales externos al espacio local y, al mismo tiempo, un crecimiento y una prosperidad que han impactado en el desarrollo local y la calidad de vida en el territorio donde se localizan sus actividades productivas (anclaje local). Este tipo de empresas, asimismo, posee la habilidad para influir sobre su propio ciclo de vida, lo cual le abre la oportunidad de iniciar una ruta de competitividad y crecimiento sostenidos.

Con dicho conocimiento, los gobiernos descentralizados estarían en posibilidad de diseñar medidas de política y programas de fomento que busquen multiplicar la ruta de éxito de las empresas innovadoras, con lo que cumplirían su misión de promover el desarrollo.

Previamente a la presentación de un marco de referencia (cuadro 1) que oriente el diseño de políticas de fomento a la pequeña empresa, es necesario realizar un diagnóstico que lleve a entender las características de las empresas locales (estado de desarrollo, potencial innovador, etcétera), que contribuirá a identificar un grupo beneficiario de firmas comprometidas con el éxito empresarial asociado al desarrollo económico local.

En el cuadro 1 se incluye también a la microempresa en virtud de su potencial para evolucionar hacia el estrato de pequeña empresa.

El esquema permite distinguir criterios para orientar el planteamiento de tipos de política asociados a diferentes estadios de

\section{Cuadro 1. Marco de referencia para el diseño de políticas de fomento} a la pequeña empresa

\begin{tabular}{|c|c|c|c|c|}
\hline \multirow{2}{*}{$\begin{array}{l}\text { Estadio de la firma } \\
\text { Potencial emprendedor-innovador }\end{array}$} & \multicolumn{2}{|c|}{ Microempresa } & \multicolumn{2}{|c|}{ Pequeña empresa } \\
\hline & Start-Up & > 3 años & Seguidor & Innovador \\
\hline
\end{tabular}

Factores de éxito en dos niveles:

Nivel 1: Intervenciones orientadas a crear una base de estabilidad en la gestión y sostenibilidad de resultados.

Nivel 2: Intervenciones orientadas a movilizar el potencial endógeno de crecimiento y poder de negociación. 
vida de la firma y a los principales desafíos en cada uno de ellos. Como criterio orientador para el empleo del marco de referencia se recomienda tomar en consideración la lógica que sigue el argumento presentado a continuación.

En países en vías de desarrollo, los nuevos negocios se inician en un estadio pequeño, lo que es consistente con la noción de microempresa. Diversos estudios muestran que los niveles más altos de mortandad ocurren dentro de los primeros tres años de vida. Por ende, las medidas de fomento en esta fase tendrán un sesgo paternalista, pero de carácter temporal.

En una fase posterior, el objetivo es fomentar la transición de microempresa a pequeña empresa, lo cual supone ventajas de mayor estabilidad en la gestión y la autosostenibilidad en los resultados del negocio. Superada esta fase, surge el desafío de decidir si el destino de la firma estará sujeto a las prioridades de supervivencia y/o rentabilidad del fundador o a las perspectivas de superar los actuales niveles de desempeño (innovación, competitividad, entre otros factores) para obtener un mejor posicionamiento en el mercado.

Si las perspectivas de crecimiento predominan, ello significará que la firma ha internalizado las ventajas del crecimiento y la innovación. En este caso, las medidas de fomento deben enfocarse a facilitar la transición de la pequeña empresa hacia un estadio de mediana empresa o, en su defecto, a un estadio en el que esta desarrolle una red de cooperación y sinergias con empresas locales y externas, al mismo tiempo que aumenta su grado de incidencia en la competitividad y el desarrollo económico de su espacio local.
A modo de ejemplo, en el cuadro 2 se presenta un conjunto de políticas de fomento que distingue las fases o estadios en la evolución de la pequeña y microempresa.

\section{Conclusiones}

El propósito del presente artículo ha sido ampliar el análisis del proceso emprendedor desde una perspectiva de desarrollo, privilegiando la innovación y el fomento a las fuerzas endógenas que lo alimentan.

El énfasis en la promoción del desarrollo local (endógeno) está asociado a procesos de descentralización y transferencia de competencias del gobierno nacional a los gobiernos descentralizados o subnacionales. En el caso del Perú, la transferencia de competencias en materia de desarrollo económico local recae en los gobiernos locales, con un énfasis explícito en el fomento a la pequeña empresa.

No obstante, a pesar del tiempo transcurrido desde el inicio del proceso de descentralización, en enero de 2003, los gobiernos locales no han logrado resultados ni tenido incidencia en materia de promoción del desarrollo económico de su zona, ni de fomento a la competitividad de las pequeñas y microempresas del área. Los motivos para este modesto desempeño son variados e incluyen restricciones presupuestales, incipiente entendimiento de la dinámica de las pequeñas empresas $\mathrm{y}$, especialmente, ausencia de políticas locales de fomento a estas empresas, de manera tal que impulsen la economía y el desarrollo local.

En este contexto, se ha propuesto un marco de referencia que permitirá orientar el diseño de políticas públicas locales 


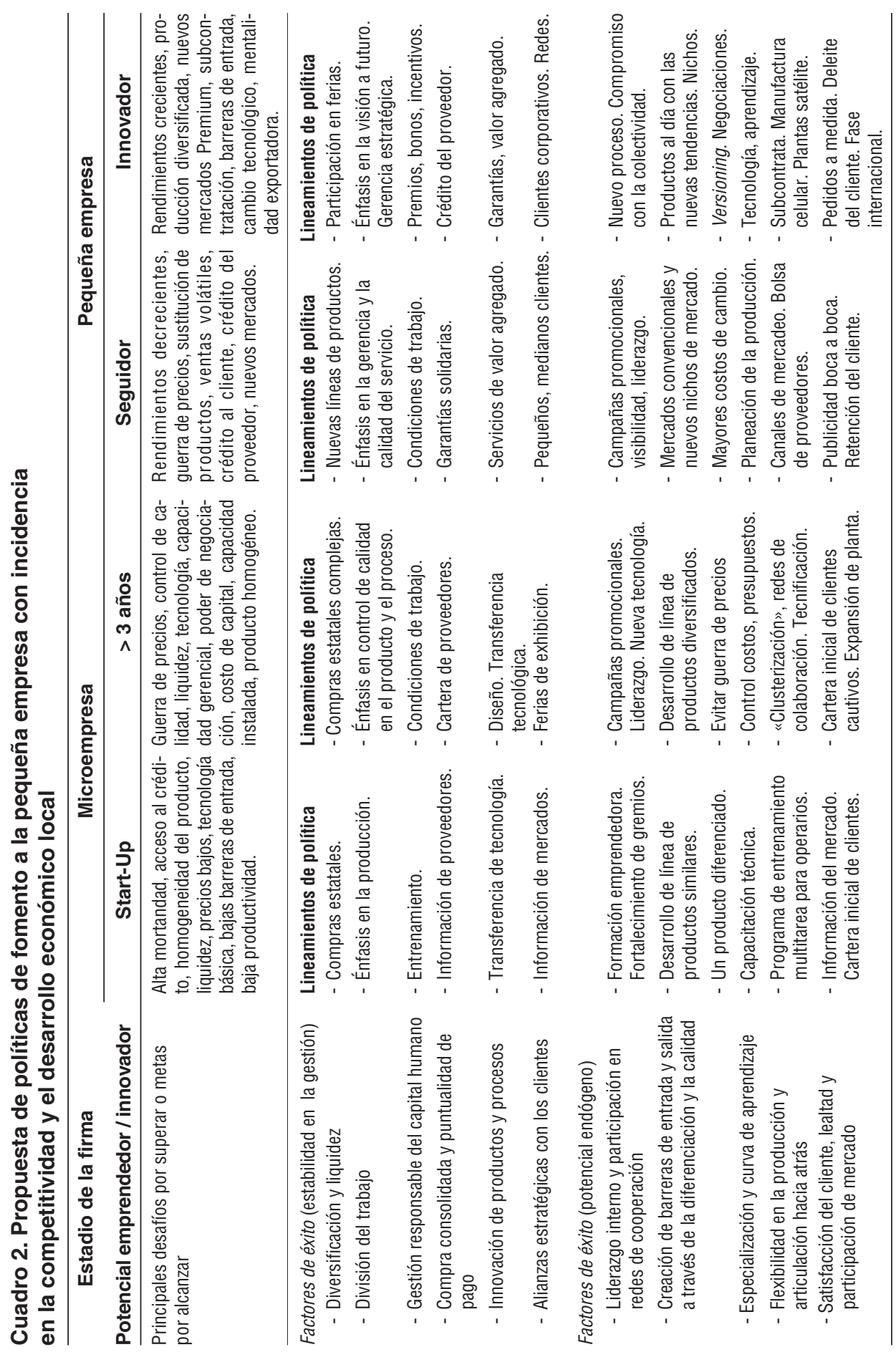


destinadas a concertar esfuerzos públicos y privados para promover la competitividad de la pequeña empresa, de modo que se generen externalidades positivas para el desarrollo del territorio local, se multipliquen los casos de éxito empresarial y se generen vinculaciones con sistemas productivos externos.

El diseño resultante considera tres dimensiones de análisis. La primera destaca que el éxito económico local no se explica por la dimensión puramente empresarial, sino que depende de condiciones planificadas en el territorio que faciliten los emprendimientos y que contribuyan a la prosperidad de aquellas unidades económicas con mayor incidencia en el bienestar y el desarrollo local. Fallar en este aspecto puede conducir a replicar la falta de impacto de intervenciones pasadas (impulsadas por el gobierno nacional y la cooperación técnica) que no fueron sostenibles o que se circunscribieron a un grupo mínimo de beneficiarios, sin mayor impacto en la competitividad del territorio y la calidad de vida de la sociedad local.

La segunda dimensión de análisis busca llamar la atención sobre un tipo particular de emprendimientos locales que, indepen- dientemente de programas de fomento en su área de influencia, han conseguido construir una ruta de éxito económico y crecimiento empresarial sobre la base de la innovación permanente. Esta trayectoria, se sostiene, ha permitido que las microempresas superen las restricciones de tamaño y transiten hacia el estadio de pequeña empresa, que disfruten de mayores y mejores negocios con proveedores y clientes locales y externos y que desarrollen una cultura ganar-ganar que genera impacto en las condiciones laborales de sus trabajadores y operarios y en el desarrollo local.

La tercera dimensión de análisis introduce la noción de ciclo de vida. Este criterio es útil para focalizar el diseño e implementación de políticas en función de los estadios de desarrollo en que se encuentran las empresas que serán beneficiarias de las medidas de fomento (políticas, programas y proyectos).

Los criterios presentados permitirían aprender de casos de éxito, en los que la innovación y el crecimiento tuvieron incidencia en el desarrollo local, y, a partir de ello, diseñar medidas de fomento sostenibles y con efecto multiplicador en la calidad de los emprendimientos locales. 


\section{Referencias bibliográficas}

ALDRICH, H. y MARTÍNEZ, J. E. 2001. Many are Called, but Few are Chosen: An Evolutionary Perspective for the Study of Entrepreneurship. Entrepreneurship: Theory and Practice. Vol. 25, n. ${ }^{\circ}$ 4, págs. 41-57.

AMIT, R.; GLOSTEN, L. y MUELLER, E. 1993. Challenges to Theory Development in Entrepreneurial Research. Journal of Management Studies. Vol. 30, n. ${ }^{\circ}$, págs. 815-834.

AUDET, José y D'AMOISE, Gerald. 1998. The Relationship Between Strategic Scanning Activities of Small and Medium-Sized Enterprises and their Performance: A Multi-site Study Approach. Proceedings of the United States Association of Small Business and Entrepreneurship. <http://www.sbaer.uca. edu/Research/1998/USASBE/98usa296.txt> (24 de jun., 2003).

BECKER, M. 2004. The Role of Entrepreneurship in Economic and Technological Development: Schumpeter's Contribution to Understanding Entrepreneurship. Proceedings of the DRUID Summer Conference 2004 on Industrial Dynamics, Innovation and Development, Elsinore, Dinamrca.

CHRISMAN, J. y MCMULLAN, W. (eds.). 2002. Some Additional Comments on the Sources and Measurement of the Benefits of Small Business Assistance Programs. Journal of Small Business Management. Ciudad. Vol. 40, n. ${ }^{\circ}$, págs. 33-50.

CHRISTENSEN, C. M. 1997. The Innovator's Dilemma. Boston: Harvard Business School.

CONFERENCIADE LAS NACIONES UNIDAS SOBRE COMERCIO Y DESARROLLO (UNCTAD). 2001. Informe sobre las inversiones en el Mundo. Nueva York: Naciones Unidas.
GALLO, M. 1998. La sucesión en la empresa familiar. Barcelona: Colección Estudios e Informes La Caixa.

1996. La empresa familiar. Barcelona: Ediciones Folio. Biblioteca IESE de Gestión de Empresas, Universidad de Navarra.

HIGH, J. 2004. The Roles of Entrepreneurship in Economic Growth: Toward a Theory of Total Factor Productivity. En: De Groot, Henri; Nijkamp, Peter y Stough, Roger R. (eds.). Entrepreneurship and Regional Economic Development. Cheltenham: Edward Elgar. págs. 46-77.

HUNTINGTON, S. P. 1997. El choque de civilizaciones. Barcelona: Paidós Ibérica.

INTER-AMERICAN DEVELOPMENT BANK. 2002. Entrepreneurship in Emerging Economies: The Creation and Development of New Firms in Latin America and East Asia, Washington D.C.: IADB Publications.

KIMBERLY, J. R. y MILES, R. H. 1980. The Organizational Life Cycle: Issues in the Creation, Transformation, and Decline of Organizations. San Francisco: Jossey-Bass.

LESTER, D. L. y PARNELL, J.A. 2002. The Complete Life Cycle of a Family Business. $<$ http://www.sbaer.uca.edu/research/asbe/2004/PDFS/25.pdf> (10 de jun., 2005).

LONGENECKER, J. G.; MOORE, C. W. y PETTY, J. W. 2001. Administración de pequeñas empresas: un enfoque emprendedor. México: Internacional Thomson.

MCCANN, P. y ARITA, T. 2004. Industrial Clusters and Regional Development: A Transaction-Costs Perspective on the Semiconductor Industry. En: De Groot, Henri; Nijkamp, Peter y Stough, Roger R. (eds.). 
Entrepreneurship and Regional Economic Development. Cheltenham: Edward Elgar. págs. págs. 225-251.

MEJÍA, R. 2002. Definición de la micro y pequeña empresa. $<$ http://www.monografias. com/trabajos11/pymes/pymes.shtml $>$ (21 de jun., 2007).

NONAKA, I. y TAKEUCHI, H. 1995. The Knowledge-Creating Company: How Japanese Firms Create the Dynamics of Innovation. Oxford: Oxford University Press.

OECD.1997. Small Businesses, Job Creation and Growth: Facts, Obstacles and Best Practices, París: OECD.

1996. SMEs: Employment, Innovation and Growth. París: OECD.

REINERT, E. 1996. The Role of Technology in the Creation of Rich and Poor Nations. Underdevelopment in a Schumpeterian System. En: Derek, Aldcroft y Catterall, Ross E. (eds.). Rich Nations-Poor Nations: The Long Run Perspective. Aldershot: Edward Elgar. págs. 161-188.

1994. The Concept of Competitiveness and its Predecesors. <http://www.step.no/reports/ Y1994/0394.pdf> (10 de jun., 2004).

RIALP-CRIADO, A.; RIALP-CRIADO, J.; URBANO, D. y VAILLANT, N. 2003. The Born-global Phenomenon: A Multiple Case Study Research in Spain. Proceedings of the 2003 Annual Conference of the International Council for Small Business. Belfast (UK), 15-18 June, 2003, pág. 24.

ROCA, S. y VARGAS, B. 2003. Pequeña empresa: estrategias sistémicas para el crecimiento en un entorno global. Perspectiva Económica. Vol. 7, n. $^{\circ} 12$, págs. $65-82$.

2002. La transición hacia la mediana empresa y el desarrollo exportador: el caso de Acrimetal en el Perú. Cuadernos de Difusión (ESAN). Lima, dic., vol. 7, n. ${ }^{\circ}$ 13, págs. 75-99.
RUTTEN, R. y BOEKEMA, F. 2004. A Knowledge-Based View on Innovation in Regional Networks: The Case of the KIC Project. En: De Groot, Henri; Nijkamp, Peter y Stough, Roger R. (eds.). Entrepreneurship and Regional Economic Development. Cheltenham: Edward Elgar. págs. 175-197.

SCOUT, B. y LODGE, G. 1985. US Competitiveness and the World Economy. Boston: Harvard Business School.

SMALL BUSINESS ADMINISTRATION. OFFICE OF ADVOCACY. 2004. Quarterly Indicators: The Economy and Small Business. $<$ http://www.sba.gov/ADVO/stats/sbqei.pdf $>$ (21 de jul., 2004).

STIGLITZ, J. E. 2002. El malestar en la globalización. Buenos Aires: Taurus.

SUÁREZ-VILLA, L. 2004. Technocapitalism and the New Ecology of Entrepreneurship. En: De Groot, Henri; Nijkamp, Peter y Stough, Roger R. (eds.). Entrepreneurship and Regional Economic Development. Cheltenham: Edward Elgar. págs. 78-103.

TORRES, O. 2003. Thirty Years of Research into SMEs: Trendes and Counter-Trends in the Quest for Disciplinarity. En Watkins, David (ed.) Annual Review of Progress in Entrepreneurship Research (Southhampton Business School, Reino Unido). Vol. 2, 20022003, págs. 37-84.

VARGAS, B. 2004a. Políticas públicas locales y desarrollo. Cuadernos de Difusión (ESAN). Lima, dic., vol. 9, n. ${ }^{\circ} 17$, págs. 47-59.

2004b. The Creative Path of Innovative Entrepreneurs: Small Details that Make Big Things to Happen. Ponencia presentada en: EFMD $34^{\text {th }}$ Conference on Entrepreneurship, Innovation and Small Business. 8-10 set., Turku, Finlandia.

VILLARÁN, F. 2000. Las pyme en la estructura empresarial peruana. $<$ http://decon.edu. uy/network/panama/VILLARAN.PDF $>$ (19 de ago., 2003). 